\title{
Application of Environment-Friendly Solid Supported Acid Catalyst for Hydrolysis of Jaggery
}

\author{
Hemantini Deshpande, Sudharshana Kakade, Khudbudin Mulani* \\ Directorate of Forensic Science Laboratories, Santacruz(E), Mumbai (MS), India
}

*Corresponding Author: Khudbudin Mulani, Directorate of Forensic Science Laboratories, Santacruz (E), Mumbai (MS), India-400098, Email: kbchemorg@gmail.com

\begin{abstract}
In the present study, we described simple and cost effective method for hydrolysis of jaggery. Silica sulfuric acid was used as solid acid catalyst for hydrolysis of jaggery. Silica sulfuric acid was simply prepared by immobilizing sulfuric acid on silica gel. The key advantages of this solid acid catalyst are efficiency, reusability, easy work-up, no corrosion and environment-friendly catalyst for hydrolysis.
\end{abstract}

Keywords: Jaggery, silica sulfuric acid, hydrolysis, green chemistry

\section{INTRODUCTION}

Jaggery is known as 'Gur' in North India. Jaggery is available in solid, liquid and powder form and also known as eco-friendly nutritive sweetener. Jaggery is produced dominantly in sugarcane growing areas of different states of India. In Maharashtra, Kolhapur is one of the largest producers of jaggery. In India, about 10.3 million tonnes of jaggery is produced annually [1]. Jaggery contains glucose (10$15 \%)$, protein $(0.25 \%)$, fats $(0.05 \%)$, calcium $(0.4 \%)$ iron $(11 \mathrm{mg} / 100 \mathrm{gm})$ and copper $(0.8$ $\mathrm{mg} / 100 \mathrm{mg}$ ) [2].

Jaggery gained lot of importance in the Indian diet. Along with that, jaggery is useful for production of alcohol through fermentation method. In fermentation, the anaerobic oxidation of organic molecule by enzyme action. Gakkar and Nair described method in which alcohol have been produced by fermentation method and concentration of alcohol determined in the sugarcane and jaggery. The results indicates that alcohol concentration present in jaggery sample $(1.1 \%)$ greater than sugarcane sample $(0.8 \%)$ [3].

In rural areas of Maharashtra, jaggery is frequently used for production of ethyl alcohol. This method of production of ethyl alcohol from jaggery is totally illegal. In such cases police authorities and state excise officials seized jaggery samples and sends to forensic laboratory for analysis. In forensic point of view, it is necessary to have simple and cost effective method for analysis of jaggery samples. In forensic laboratory, jaggery is analyze by testing different parameters and hydrolysis of jaggery is one of them most important parameter. Forensic experts used different acid catalysts like hydrochloric acid, sulfuric acid and chlorosulphonic acid. The hydrochloric acid is traditionally used by forensic expert for hydrolysis of jaggary. However, use of these acids suffers from several problems like corrosion, catalyst recovery and producing waste [4-6].

Use of silica sulfuric acid as heterogeneous acid catalyst has the potential to overcome the above drawbacks due to the ease separation of catalyst, reusability of catalyst and eco-friendly nature.

\section{Material AND MethodS}

\subsection{Chemicals and Reagents}

Sodium hydroxide and methylene blue reagent were procured from Thomas baker (chemicals) Pvt. Ltd., India. Sulfuric acid was purchased from Rankem Pvt. Ltd., India. Diethyl ether and copper sulfate are procured from S. D. Fine Chem Ltd. India. Silica gel (200-400 mesh) was received from Loba Chemie Pvt. Ltd. India. Sodium potassium tartarate was purchased from Molychem Pvt. Ltd., India. All chemicals were used as received without any purification.

\subsection{Preparation of Fehling $A$ and Fehling $B$ Solution}

Fehling A: To the $500 \mathrm{~mL}$ of volumetric flask, dissolved $34.64 \mathrm{gm}$ of copper sulfate and 0.5 
$\mathrm{mL}$ of concentrated sulfuric acid in distilled water and diluted upto $500 \mathrm{~mL}$ with distilled water.

Fehling B: To the $500 \mathrm{~mL}$ of volumetric flask, dissolved $176 \mathrm{gm}$ of sodium potassium tartarate and $77 \mathrm{gm}$ of sodium hydroxide in distilled water and diluted upto $500 \mathrm{~mL}$ with distilled water.

Standard glucose solution: $0.5 \mathrm{gm}$ glucose dissolved in $100 \mathrm{~mL}$ of water

Preparation of jaggery solution: 5 gm of jiggery dissolved in $250 \mathrm{~mL}$ of distilled water

Preparation of invert sugar solution: 1) In 250 $\mathrm{mL}$ of volumetric flask, pipette out $25 \mathrm{~mL}$ of $2 \%$ jiggery solution followed by $5 \mathrm{~mL}$ of concentration hydrochloric acid was added. Kept above solution aside for overnight and then neutralize with sodium hydroxide solution. 2) In $250 \mathrm{~mL}$ of volumetric flask, pipette out $25 \mathrm{~mL}$ of $2 \%$ jiggery solution followed by 0.5 gm SSA catalyst was added. Kept above solution aside for two hours and then neutralize with sodium hydroxide solution.

\subsection{Preparation of Silica Sulfuric Acid (SSA)}

The solid supported silica sulfuric acid was prepared according to the procedure reported [7]. To the mixture of $10 \mathrm{gm}$ of silica gel and 50 $\mathrm{mL}$ of diethyl ether, $3 \mathrm{~mL}$ of concentrated sulfuric acid was added with shaking for five minutes. Excess of solvent was evaporated to obtain dry silica sulfuric acid catalyst which was then heated at $120^{\circ} \mathrm{C}$ for $3 \mathrm{~h}$. The silica sulfuric acid was stored at clean and dry place.

\section{RESULTS AND DISCUSSION}

\subsection{Standardization of Fehling A and Fehling B}

Accurately fill burette by standard glucose solution and make sure to remove any bubbles. Pipette out $5 \mathrm{~mL}$ each of Felhing A and B solution in $100 \mathrm{~mL}$ of conical flask. Above solution was heated on wire gauze $\left(70{ }^{\circ} \mathrm{C}\right)$ and added drop wise standard solution of glucose from burette till the color changes from blue to reddish-brown. Then, 1-2 drops of 1\% solution of methylene blue reagent was added and again heat the solution and added drop wise standard solution of glucose from burette till the end point color changes from blue to brown (brick red) precipitate. Burette reading was note recorded and repeats the titration for duplicate.

\subsection{General Titration Method for Estimation of Sugar}

In $250 \mathrm{~mL}$ conical flask, pipette out $10 \mathrm{ml}$ of Fehling ( $5 \mathrm{ml}$ of each Fehling A and B). Fill the burette with jaggery solution. Add into the flask almost the whole volume required to reduce the Fehling mixture drop wise till color changes blue to brown. Boil the contents for 1-2 minutes and then add 2 drops of methylene blue indicator. Followed by jaggery solution was added drop by drop to complete the titration to the appearance of brick red color. Reducing sugar, total sugars and non-reducing sugar were determined by well known formulas reported elsewhere [8].

\subsection{Effect of Type of Catalyst}

Generally, hydrolysis of jaggery is carried out using strong protic acids such as hydrochloric acid, sulfuric acid, trifluoro-acetic acid and nitric acid. However, all above mentioned acid catalysts are corrosive when using directly and they can cause heavy environmental pollution because these catalysts are difficult to separate from reaction mixture. These catalysts suffer from longer reaction time, difficult to workup and often give unsatisfactory yield. Therefore, it is important to develop new method to overcome these disadvantages. Therefore, we have used silica supported sulfuric acid as a solid supported acid catalyst for hydrolysis of jaggery. In this study, we used concentrated hydrochloric acid and silica sulfuric acid for hydrolysis of jaggery. The results of hydrolysis of jaggery by using hydrochloric acid and silica sulfuric acid are summarized in Table 1.

Table1: Hydrolysis of sugar using different acid catalysts

\begin{tabular}{|l|l|l|l|}
\hline Catalyst & \% of reducing sugar & \% of invert sugar & \% of non-reducing sugar \\
\hline Conc. HCl & 13.0 & 92.0 & 75.0 \\
\hline Silica sulfuric acid & 14.2 & 90.0 & 73.0 \\
\hline
\end{tabular}

This result clearly indicates that, the reaction proceeded very efficiently with good results when silica sulfuric acid was used. The results obtained using concentrated hydrochloric acid and silica sulfuric acid showed almost equal percentage of conversion. The results obtained by using silica sulfuric acid influenced us to carry out the reaction under greener and mild reaction condition. 


\subsection{Effect of Amount of Catalyst}

The hydrolysis of jaggery is significantly influenced by the amount of acid catalyst. The hydrolysis of jaggery was studied with respect to the amount of solid acid catalyst. The Table2: Effect of concentration of SSA catalyst concentration of silica sulfuric acid catalyst was varied from $0.1 \mathrm{gm}$ to $0.5 \mathrm{gm}$. The effect of acid catalyst concentration on hydrolysis of jiggery is depicted in Table 2 .

\begin{tabular}{|l|l|l|l|}
\hline Silica sulfuric Acid (g) & \% of reducing sugar & \% of invert sugar & \% of non-reducing sugar \\
\hline $\mathbf{0 . 1}$ & 14.2 & 56.0 & 41.0 \\
\hline $\mathbf{0 . 2}$ & 14.2 & 59.0 & 43.0 \\
\hline $\mathbf{0 . 3}$ & 14.2 & 62.0 & 47.0 \\
\hline $\mathbf{0 . 4}$ & 14.2 & 70.0 & 54.0 \\
\hline $\mathbf{0 . 5}$ & $\mathbf{1 4 . 2}$ & $\mathbf{9 0 . 0}$ & $\mathbf{7 3 . 0}$ \\
\hline $\mathbf{0 . 6}$ & 14.2 & 88.0 & 70.0 \\
\hline
\end{tabular}

At lower concentration of catalyst, percentage of hydrolysis of jaggery was lower. The percentage hydrolysis increases with increase in concentration of silica sulfuric acid. The highest percentage of hydrolysis was observed, when $0.5 \mathrm{gm}$ silica sulfuric acid catalyst used. However, concentration of acid catalyst higher than $0.6 \mathrm{~g}$, there is no drastic change in percentage hydrolysis. Therefore, equilibrium concentration of silica sulfuric acid catalyst for hydrolysis of jaggery is $0.5 \mathrm{~g}$.

\subsection{Effect of Contact Time}

The time of contact has a significant effect on

Table3: Effect of contact time the hydrolysis of jaggery using silica sulfuric acid. The hydrolysis experiment was carried out with respect to contact time ranging from 30 to 120 minutes.

The obtained results are presented in Table 3. These results indicated that percentage hydrolysis of jaggery was lower when reaction time was lower. The percentage hydrolysis of jaggery increases with increase in reaction time. The percentage hydrolysis of jaggery reaches higher value at 90 minutes reaction time. Further increase in reaction time has a negligible effect on the percentage hydrolysis of jaggery.

\begin{tabular}{|l|l|l|l|}
\hline Time (min) & \% of reducing sugar & \% of invert sugar & \% of non-reducing sugar \\
\hline $\mathbf{3 0}$ & 14.0 & 76.0 & 60.0 \\
\hline $\mathbf{6 0}$ & 14.0 & 88.0 & 70.0 \\
\hline $\mathbf{9 0}$ & $\mathbf{1 4 . 0}$ & $\mathbf{9 2 . 0}$ & $\mathbf{7 4 . 0}$ \\
\hline $\mathbf{1 2 0}$ & 91.0 & 73.0 \\
\hline
\end{tabular}

\subsection{Reusability of Catalyst}

The reusability of the catalyst is important process to reduce environmental pollution as well as process cost. We also investigated the reusability and recycling effect of silica sulfuric acid catalyst in hydrolysis reaction. At the end of each reaction, the catalyst was isolated by filtration, then washed with diethyl ether followed by dried at $120^{\circ} \mathrm{C}$ for $3 \mathrm{~h}$, and reused in a sub-sequent reaction cycle. The recycled catalyst was employed consecutively for three times for hydrolysis of jaggery and there are no significant loss in its efficiency of silica sulfuric acid catalyst was observed.

\section{Conclusions}

In summary, a convenient and facile methodology has been developed for hydrolysis of jaggery in presence of solid supported silica sulfuric acid. In this method, we used silica sulfuric acid instead of traditionally used protic acids. Silica sulfuric acid gave more efficient results and ease to separate catalyst from reaction media. Overall, we have been able to develop greener and environmentally friendly method for the hydrolysis of jaggery.

The reusability, short reaction time and good yield are the key advantage of this method to existing procedures may attract the forensic expert.

\section{ACKNOWLEDGEMENTS}

The authors express gratitude to Dr. K. V. Kulkarni, Director, Forensic Science Laboratories, State of Maharashtra, Santacruz(E), Mumbai for their keen interest and valuable guidance in this work.

\section{REFERENCES}

[1] Dorage S., Proceeding of national consultation meeting. Feb 27-28: I- III (1994).

[2] Ramkrishna R., Satanarayana Y., Padma Raju A., Proceeding of national consultation meeting. Feb 27-28:109-110 (1994). 
[3] Gakkhar N., Nair R., Production of Alcohol through Fermentation in Saccharum Officinarum (Sugarcane) and Jaggery (Gur). Inter. J. Rec. Res. Rev. 4(2): 1 (2013).

[4] Bentley T., Jurczyk S., Roberts K., Williams D., Ester hydrolysis in aqueous sulphuric acid effects of solvent ionizing power and nucleophilicity separated from the effects of protonation of substrate. Journal of the Chemical Society, Perkin Transactions. 2:293299 (1987).

[5] Strazzolini P., Scuccato M., \& Giumanini A., Deprotection of t-butyl esters of amino acid derivatives by nitric acid in dichloromethane. Tetrahedron. 56:3625-3633 (2000).
[6] Strazzolini P., Misuri N., Polese P., Efficient cleavage of carboxylic tert-butyl and 1adamantyl esters, and NBoc-amines using $\mathrm{H}_{2} \mathrm{SO}_{4}$ in $\mathrm{CH}_{2} \mathrm{Cl}_{2}$, Tetrahedron Letters. 46:2075-2078 (2005).

[7] Zolfigol M., Silica sulfuric acid/NaNO2 as novel heterogeneous system for production of thionitrites and disulfides under mild conditions. Tetrahedron. 57: 9509 (2001).

[8] Mohana Kumara Nayaka. Standardization of procedure for liquid jaggery making and utilization for value addition. $\mathrm{PhD}$ thesis, Department of food science and nutrition University of agricultural sciences Bengalore, (2009).

Citation: Khudbudin Mulani, et.al. Application of Environment-Friendly Solid Supported Acid Catalyst for Hydrolysis of Jaggery. ARC Journal of Forensic Science. 2020 5(1):24-27. http://doi.org/10.20431/24560049.0501005 .

Copyright: (C) 2020 Authors. This is an open-access article distributed under the terms of the Creative Commons Attribution License, which permits unrestricted use, distribution, and reproduction in any medium, provided the original author and source are credited. 